\title{
Solve Complex Simulations to Enhance Product Performance in Naval Industry
}

\author{
Mirela Koci \\ ( PhD Cand., Politechnic University of Tirana) \\ INOVATION, RESEARCH AND START - UP CENTER, VLORE
}

\begin{abstract}
Overview Engineering successful, innovative products in today's competitive environment requires simulation power. The ability to analyze the multifaceted physical performance characteristics of a design before making a prototype can substantially increase productivity. Companies need robust simulation tools to efficiently overcome time, budget, and quality demands. The aim of this paper there is to present an inovative tool for project design SolidWorks ${ }^{\circledR}$ Simulation delivers powerful simulation capabilities that can solve complex analysis problems, helping us to design better, more innovative products faster and more cost-effectively. Also throught this article will be presented the results achived on structure analyse of composite materials used for small boats and yahts production.
\end{abstract}

Key words: project design, Alfasolid software, structural analyse, composite materials, simulation

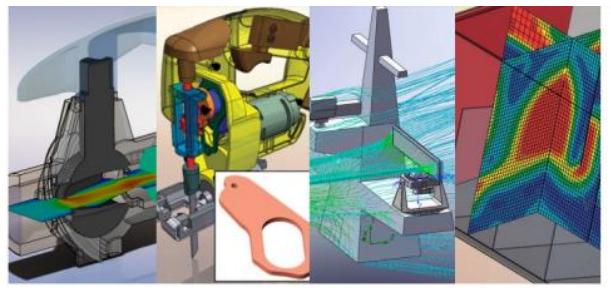

Fig. 1

\section{Introduction}

Composite materials are widely becoming the material of choice for many structural and nonstructural applications. The aircraft industry for example, has used composites for wing skins and other control surfaces that provide savings in fuel consumption and weight. The marine industry incorporates thick single skin and sandwich composites for hulls, decks, risers and other primary structure, and the automotive industry uses composites to fabricate body panels, springs and drive shafts. The civil engineering community uses glass and carbon reinforced plastics in the repair of aging bridges, piers, columns and other structures vital to the nation's infrastructure and economy.

Use of composite materials in naval industry it is developed in wider area from big companies and SME-s that produce small boats. Have been identificated during the time the really need for project design of boats and ships based on composite materials as inovative advance materials. Analysing the structural parametres using the software tools

\section{Tools and Methodology}

ALFA SOLID WORK SIMULATION tool is a very innovative one that offer great posibilities to the young engineers, constructors, engineering project designers to simulate different project creates prototype structures using differerent advanced materials. 
Simulating complex physics drives innovation. Innovative. Reliable. Efficient. These are not only the characteristics of successful product designs but also of the design and engineering organizations that create them. To develop products with these attributes, it is needed to gain as much information as we can about how our design will perform under real world conditions, and be able to obtain these insights as quickly as possible. Manufacturers no longer have the luxury of performing lengthy physical tests to understand how a design will behave. Bringing innovative, reliable products to market quickly requires simulation technology. And not just any simulation package will do. In many cases, we will need to simulate complex physical behaviors requiring powerful nonlinear, dynamics, fluid flow, and multi-physics analysis capabilities. By simulating the complex physics impacting our designs, we will gather critical information that will help us to make important design decisions.

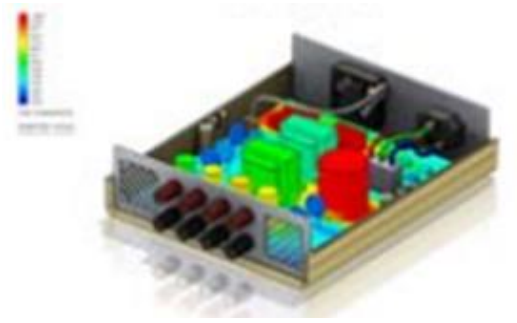

Fig. 2 Simulating comple physics drive

Using SolidWorks Simulation software to more easily conduct sophisticated analyses, we can obtain this information faster than ever. SolidWorks Simulation provides accurate, efficient solutions to resolve difficult analysis problems, accelerating time-to-market, optimizing material usage, minimizing design uncertainty, eliminating errors, preventing returns/warranty claims, and increasing profitability.

2 Multiphysics thermal simulation can ensure product performance. The possibility of a hand held device being dropped must be accounted for in the design simulations. Nonlinear structural analysis problems generally fall within three categories: nonlinear materials, nonlinear geometries, and nonlinear interactions between parts. Of course, we may face a simulation challenge that involves all three. We may be using a hyper-elastic material-such as an elastomer-in a shape that constitutes both structural nonlinearities, where the response varies disproportionately to the applied forces, and geometric nonlinearities, where displacements alter a structure's stiffness. The practical applications of nonlinear materials analysis vary widely. In a nonlinear analysis of a component, "failure" may be defined by the extent that a material yields rather than if the materials yields, as in linear analysis.
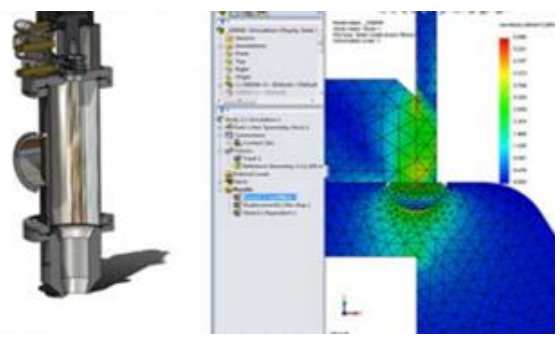

Fig 3 Multiphysic thermal analyse

We may also want to examine different failure modes, such as buckling, snap-through, "oil-canning effects," or large displacements. Many modern materials, such as plastics, synthetics, and composites, have unique properties that require nonlinear materials analysis to capture their complex load response behavior

\section{Simulating the real world requires multiphysics analysis}

While a large portion of simulation problems examine a particular type of physical phenomena-such as nonlinear structural, dynamics, fluid dynamics, and thermal analyses-there are many situations that require a combined multi- 
physics approach. Examples of multi-physics simulations include thermal stress or thermo-mechanical (thermal/structural), fluid structural interaction (flow/structural), fluid flow with heat transfer (flow/thermal), and fluid structural interaction with heat transfer (flow/thermal/structural).

Most products are not deployed in environments that maintain a single uniform temperature, and many products are subjected to heating and cooling cycles that can affect a structure's mechanical integrity and response. This tool helped us to analyze the impact of heat on structural performance. For example, in some cases, the distribution of heat within a structure can influence how a design will deform, and conversely, structural deformation can affect the ways that heat moves throughout a structure. Sometimes, the nature of this interaction is primarily in one direction-the structural response alters thermal behavior or thermal responses affect structural performance. At other times, the interaction is both ways, when each type of physical response impacts the other. This is an interactive process that often requires a nonlinear thermal/structural analysis to simulate correctly.

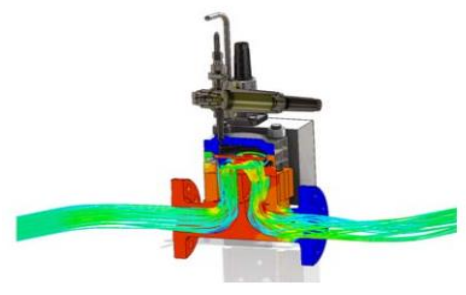

Fig 4 Analyse of hit structural performance

Multi-physics analysis with SolidWorks Simulation enables us to study the combined impact of different types of physical phenomena, such as the interaction between structural and thermal effects. In addition to situations where the interplay of two types of physical phenomena is of interest, there are circumstances where the interaction among physical phenomena is three-fold. For instance, you are designing a system in which fluid flow alters temperature, the changes in heat transfer cause structural deformation, and the deformation changes the boundary governing the flow, which changes the nature of the flow, which affects temperature.

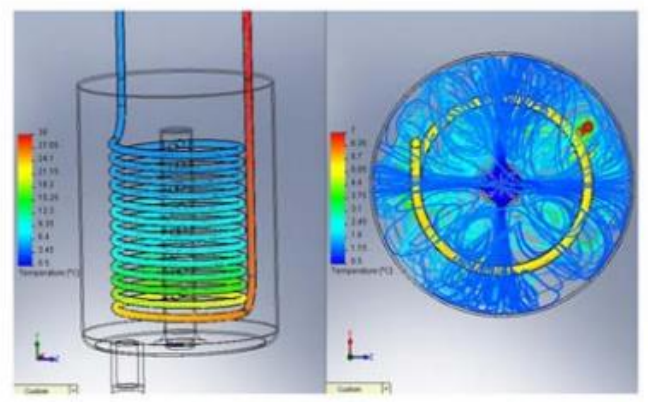

Fig. 6 Mulltiphysics analyse

\section{Model the world's complexity with SolidWorks Simulation}

The ability to predict how our designs will perform under real-world operating conditions is the essence of engineering and the purpose of prototyping. Yet, in today's competitive global market, manufacturers can no longer afford to take the time or incur the costs of conducting extensive physical testing. Increasingly, the key to engineering successful products is to leverage simulation technology to quickly and cost-effectively obtain valuable design performance information that can help us design better, more innovative products and deliver them to market. 


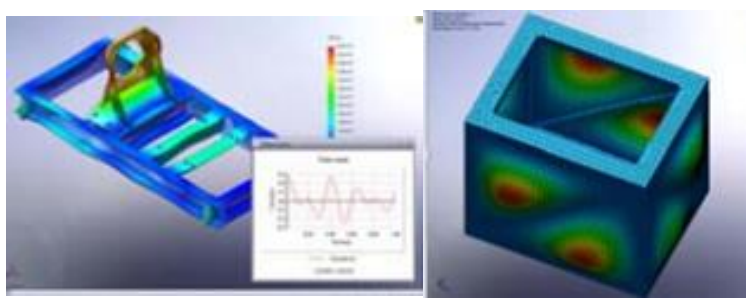

Fig 7: Model world simulation

\section{Methodology:}

Will be used step by step the metodology of project design, starting from the identification of the problem, passing to the idea and solution taking into account difefrent ones, analysing simulated them, evaluated the behaviour of our prototype and based of that select the appropriate solution, go deeper to create the apropriate prototype, simulate, test and evaluate, build and ship (see the graph)

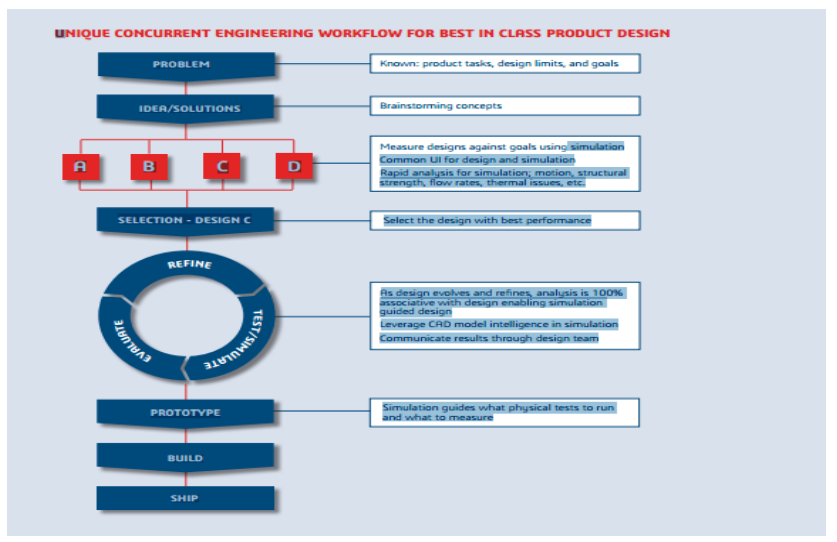

Fig 8: Engeenering work flow Alfa Solid Work

\section{Case Study: Evaluation of Structural Problems for Sandwich Composites}

From the naval industry most defects can be detected in single skin laminates and in skins of sandwich structures. There are difficulties in detecting defects that are deep inside sandwich panels with thick foam cores, and in a sandwich skin if direct access cannot be gained to the skin in question. Sandwich structures with cores of end-grain balsa are extremely difficult or impossible to inspect because the large variations in density from one balsa piece to another tend to mask all other features. Ultrasound techniques are generally the most accurate (in those cases where they work at all).

From the use of this kind of techniques have been identified the following problem in the structure.

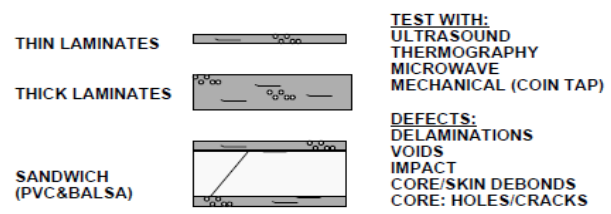

Fig 9: Structural sandwich problems. 


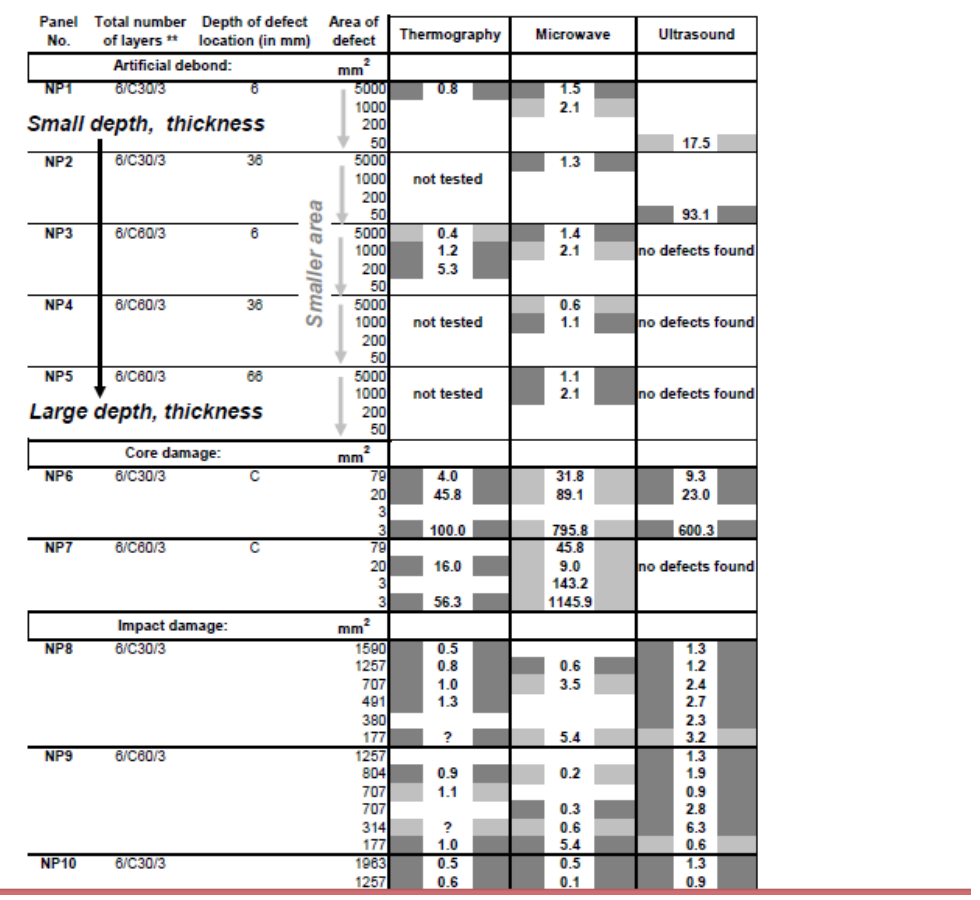

Table 1. Structural Sandwich parameters

\section{Repair Methods for Skins of Sandwich Structures}

Repair procedures were investigated for skins of sandwich structures. The durability of resins and adhesives was tested and the best candidate materials were evaluated further by repairing large beams. There is no ideal modelling approach for repaired structures, but knowing the strengths and weaknesses of each approach allows optimisation of repair geometries. The experiments were used to evaluate modelling methods and to determine how much strength can be regained in a repair. The following detailed studies were made:

- Studies to characterise and rank alternative adhesives/resins for performing both "wet" and "dry" repairs, including properties after ageing. Typical results are shown in Fig.10

- Studies of alternative geometries including scarf and step repairs with various angles and step arrangements (Fig. 11) to optimise the repair design.

- Evaluation of associated modelling approach to predict repair strength. 


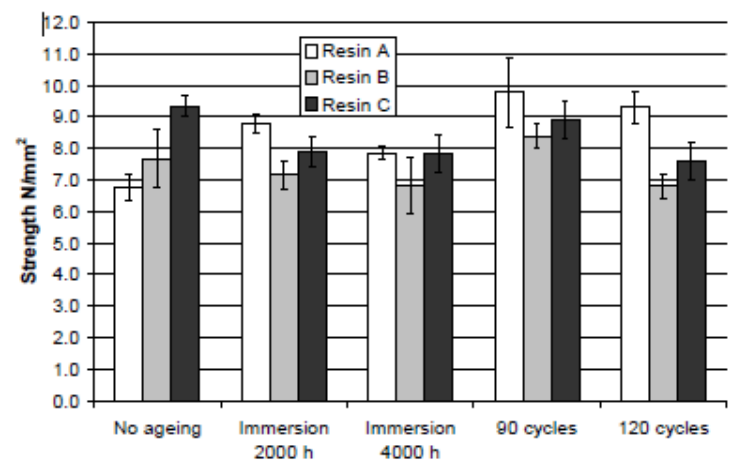

Fig 10. "Wet" and "Dry" repairs simulation results

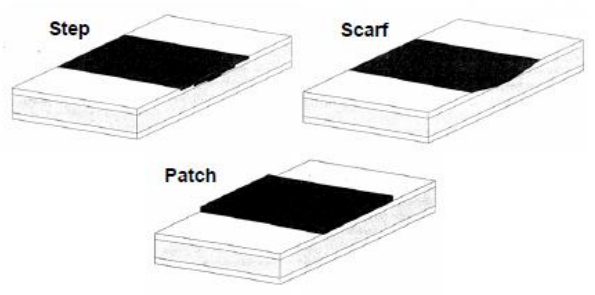

Fig 11: Sandwich Models generated from repair simulation

\section{Conclusions:}

Product Engineers can efficiently evaluate structural product performance under a wide range of physical scenarios using the powerful virtual testing environment of SOLIDWORKS Simulation Professional. Fully embedded with SOLIDWORKS 3D CAD, SOLIDWORKS Simulation Professional enables engineers to determine product mechanical resistance, product durability, natural frequencies, and test heat transfer and buckling instabilities. Pressure vessel analysis and complex loading is also supported. You can optimize products for weight, vibration, or instability based on a range of physical and geometrical parameters. With tight integration and a consistent user interface across SOLIDWORKS solutions, you can use the powerful capabilities of SOLIDWORKS Simulation Professional early in the design process to maximize product quality and reduce costs.

\section{Bibliografy:}

[1] Royal Institution of Naval Architects. Proceedings, International Symposium on Mine

[2] Warfare Vessels and Systems (3 vols.). RINA, London, 1984.

[3] Royal Institute of Naval Architects. Proceedings, Warship ' 89 - International Symposium

[4] on Mine Warfare Vessels and Systems 2 (3 vols.). RINA, London, 1989.

[5] Royal Institution of Naval Architects. Proceedings, Symposium on Small Fast Warships

[6] and Security Vessels. RINA, London, 1982.

[7] SMITH, C.S. 'Design of Marine Structures in Composite Materials'. Elsevier Applied 
[8] Science, London, 1990.

[9] HAYMAN, B. and ECHTERMEYER, A.T. 'European research on composites in high

[10] speed vessels'. Fifth International Conference on Fast Sea Transportation (FAST '99),

[11] Seattle, USA, 1999.

[12] HAYMAN, B., WIESE, M., DAVIES P., CHOQUEUSE D., HØYNING, B. and

[13] MITUSCH, P. 'Foam-Cored Sandwich Panels Under Static Pressure Loading: Some New

[14] Tests and Analyses'. 4th Int. Conf. on Sandwich Construction, Stockholm, Sweden, 9-11

[15] June 1998.

[16] AAMLID, O. 'Impact properties of different shell structures in relation to rule

[17] requirements'. Composites and Sandwich Structures, Proc. Second North European

[18] Engineering Science Conference (NESCO II), Stockholm, Sweden, 1997.

[19] WIESE, M., ECHTERMEYER, A.T., and HAYMAN, B. 'Evaluation of Oblique Impact

[20] Damage on Sandwich Panels with PVC and Balsa Core Materials'. 4th Int. Conf. on

[21] Sandwich Construction, Stockholm, Sweden, 9-11 June 1998.

[22] WEITZENBÖCK, J.R., ECHTERMEYER, A.T., ARTIGA-DUBOIS, F. and PARMAR,

[23] M. 'Nondestructive Inspection and Evaluation Methods for Sandwich Panels'. 4th Int.

[24] Conf. on Sandwich Construction, Stockholm, Sweden, 9-11 June 1998.

[25] WEITZENBÖCK, J.R., ECHTERMEYER, A.T., GRøNLUND, P.K., ARTIGA-DUBOIS,

[26] F. and PARMAR, M. 'Nondestructive Inspection and Evaluation Methods for Composites

[27] Used in the Marine Industry'. 12th Int. Conf. on Composite Materials (ICCM-12), Paris,

[28] France, 5-9 July 1999

[29] ARTIGA-DUBOIS, F., PARMAR, M., ECHTERMEYER, A.T. and WEITZENBÖCK,

[30] J.R. 'Nondestructive Testing of Composites for Naval Applications'. 20th Int. SAMPE

[31] Europe Conf., Paris, France, 1999. 